Anuar Khairullah, MBChB, MS (ORL-HNS)

Hitam Shahrul, MBBS, MMed (ORL)2

Sushil Brito -Mutuyanagam, MBBS, MS (ORL-HNS)2

'Department of Otorhinolaryngology Head \& Neck Surgery

Faculty of Medicine and Health Sciences

Universiti Sains Islam Malaysia

${ }^{2}$ Department of Otorhinolaryngology

Ampang Hospital

\section{Diffuse Idiopathic Skeletal Hyperostosis: A Rare Cause of Dysphagia}

Diffuse idiopathic skeletal hyperostosis (DISH) is a disease characterized by massive, noninflammatory ossification with intensive formation of osteophytes affecting ligaments, tendons and fascia of the anterior part of the spinal column mostly in the middle and lower thoracic regions. However, isolated and predominant cervical spinal involvement may occur. It has predilection for men (65\%) over 50 years of age and a prevalence of approximately $15-20 \%$ in elderly patients. ${ }^{1}$ A CT scan is one of the diagnostic tools. The radiographic diagnostic criteria in the spine include: 1) osseous bridging along the anterolateral aspect of at least four vertebral bodies; 2 ) relative sparing of intervertebral disc heights with minimal or absent disc degeneration; and 3) absence of apophyseal joint ankylosis and sacroiliac sclerosis. ${ }^{2}$ We present a rare case of dysphagia over two years duration due to DISH.

\section{CASE REPORT}

A 55-year-old Malay man presented with intermittent dysphagia for two years duration. He denied foreign body ingestion, globus sensation or any laryngeal trauma, shortness of breath, hoarseness or any neurological deficits. A solitary smooth mass on the right posterolateral pharyngeal wall that was hard in consistency was appreciated on oropharyngeal examination. (Figure 1) There was no significant cervical lymphadenopathy and the neurological examination was unremarkable. Cervical Radiographs and CT scan showed marked ossification at the right anterolateral aspect of cervical vertebral bodies $\mathrm{C} 2$ to $\mathrm{C} 7$ most probably representing a Diffuse Idiopathic Skeletal Hyperostosis. (Figures 2, 3) He was treated conservatively with 6-monthly follow up.

\section{DISCUSSION}

Diffuse Idiopathic Skeletal Hyperostosis (DISH) is an ossifying diasthesis characterized by the thickening and calcification of soft tissue (ligaments, tendons and joint capsule) resulting in secondary formation of osteophytes. Most commonly it affects the paraspinal ligaments, predominantly the anterior longitudinal ligament and occasionally the posterior longitudinal ligament. ${ }^{2}$ It was first described as senile ankylosing hyperostosis of the spine by Forestier and Rodes Querol in 1950. ${ }^{3}$ In 1970 Resnick et al. coined the term DISH for this systemic entity. Radiologically, they established 3-diagnostic criteria which include: 1) Presence of flowing 


\section{FEATURED GRAND ROUNDS}

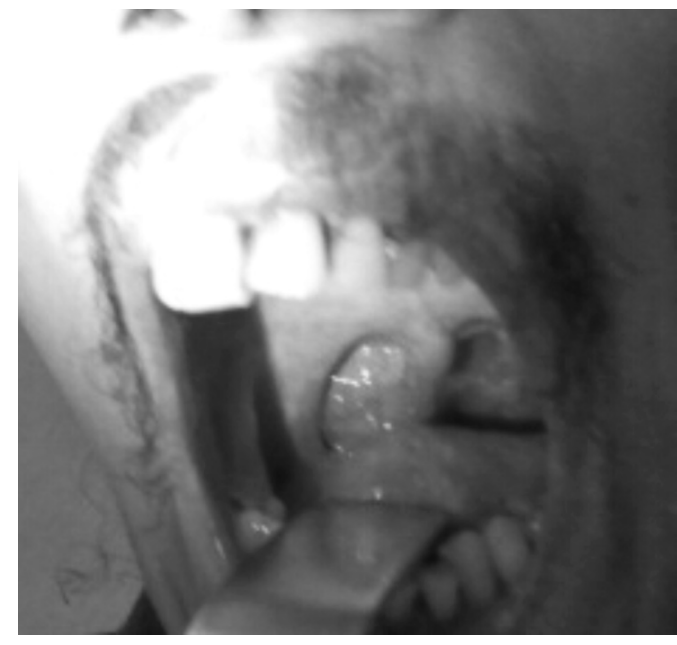

Figure 1. Right posterolateral oropharyngeal mass

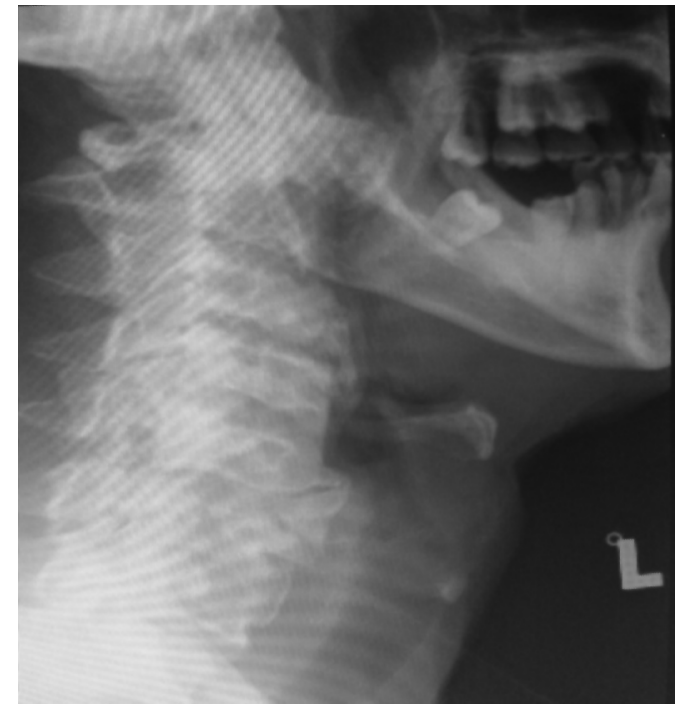

Figure 2. Lateral neck X-ray showing the osteophytes

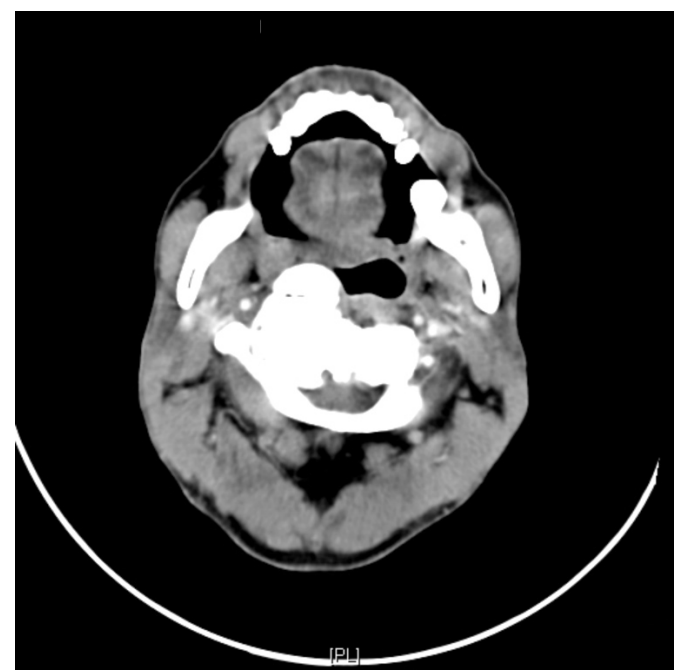

Figure 3A. CT scan, axial section showing large anterior osteophyte at C2 Level

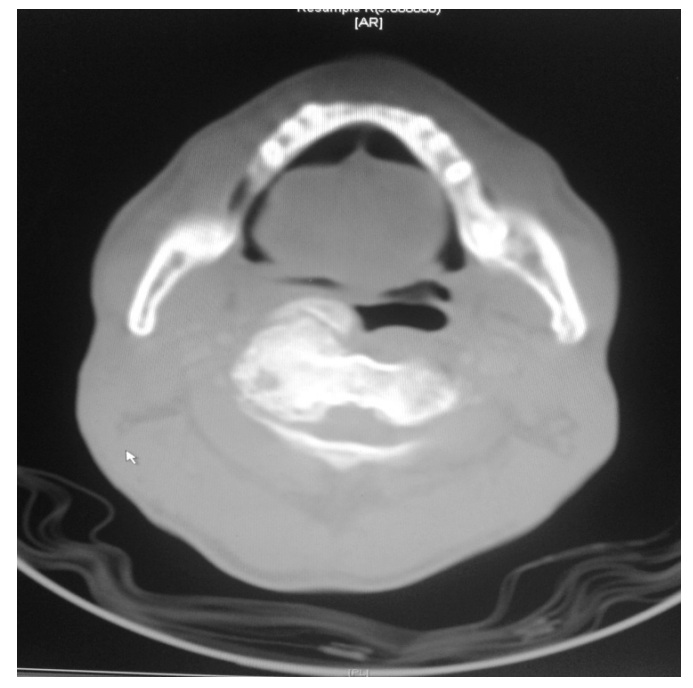

Figure 3B. CT scan, bone window at same level, showing the large anterior osteophytes

ossification of anterior longitudinal ligament of at least four contiguous vertebral bodies; 2) Preservation of intervertebral disc height; and 3) Absence of apophyseal joint ankylosis or sacroiliac joint erosion, sclerosis or fusion. ${ }^{4}$

Cervical anterior osteophytes accompanying DISH are mostly asymptomatic. They may present with cervical pain and stiffness. Large osteophytes however do cause dysphagia and it is the most common presenting complaint, affecting $17-28 \%$ of patients. ${ }^{5}$ Many different mechanisms have been suggested as the cause of the dysphagia including mass effect on the esophagus by the osteophytes and neuropathy due to recurrent laryngeal nerve impingement. ${ }^{5,6}$ According to LIn et al., in addition to distortion of laryngoesophageal anatomy and functions, osteophytes of cervical vertebrae can alter the mechanics of pharyngeal swallowing leading to secondary inflammation and edema of mucosa and soft tissue. ${ }^{6}$ Although airway symptoms in patients with DISH appear to be rare, clinicians should be aware of this condition and its potential for acute respiratory complications.

The etiology of DISH is still unclear, however according to Calisanellerr et al. it may be associated with excessive mechanical stress, hyperlipidaemia, increased levels of insulin with or without diabetes mellitus, increased levels of insulin-like growth factor-1 and hyperuricaemia.' A positive HLA-B8 has also been reported and hypervascularity may also play a role in the etiopathogenesis of DISH. $7,8,9$

Differential diagnosis of DISH includes ankylosing spondylitis, spondylosis deformans, osteoarthritis and esophageal malignancies where it should be considered when the dysphagia cannot be explained by small anterior osteophytes. ${ }^{5}$ 


\section{FEATURED GRAND ROUNDS}

Treatment can be divided into conservative treatment with dietary modification, swallowing therapy sessions and analgesia for early stages of mild dysphagia. Chiropractic treatment and acupuncture are popular alternatives among patients. The benefit of chiropractic therapy may lie in its role in increasing range of movement of the spine and providing pain relief. ${ }^{10}$ When conservative treatment fails, surgical interventions such as osteophytectomy, tracheotomy and feeding tube insertion are indicted. Surgical excision via perioral transpharyngeal route for C1 and C2 vertebrae or anterior cervical approach for C3 to C7 vertebrae is preferred. ${ }^{6,11}$ The aim of the surgery is to provide satisfactory decompression of the esophagus. ${ }^{6}$ Recent studies have shown that patients treated surgically with osteophytectomy had marked improvement if not complete resolution of their upper aerodigestive disturbances. ${ }^{11}$ It should be remembered that surgical interventions harbor the risk of recurrent laryngeal nerve injury, Horner's syndrome, cervical instability, persistent symptoms and recurrence. ${ }^{11}$

Dysphagia caused by diffuse idiopathic skeletal hyperostosis is an uncommon entity. Radiological evaluation specifically CT scans are diagnostic and can rule out other possible causes of oropharygeal mass. Surgical decompression may relieve the dysphagia when conservative treatments fail.

\section{REFERENCES}

1. Weinfeld RM, Olson PN, Maki DD, Griffiths HJ. The prevalence of diffuse idiopathic skeletal hyperostosis (DISH) in two large American Midwest metropolitan hospital populations. Skeletal Radiol 1997 Apr; 26(4):222-225.

2. Goh PY, Dobson M, Iseli T, Maartens NF. Forestier's disease presenting with dysphagia and dysphonia. J Clin Neurosci. 2010 Oct; 17(10):1336-1338.

3. Forestier J, Rotes-Querol J. Senile ankylosing hyperostosis of the spine. Ann Rheum Dis 1950 Dec; 9(4):321-330.

4. Resnick D, Niwayama G. Radiographic and pathologic features of spinal involvement in diffuse idiopathic skeletal hyperostosis (DISH). Radiology 1976 Jun; 119(3): 559-568.

5. Kos MP, Van Royen BJ, David EF, Mahieu HF. Anterior cervical osteophytes resulting in severe dysphagia and aspiration: two case reports and literature review. J Laryngol Otol. 2009 Oct; 123(10):1169-1173.

6. Lin HW, Quesnel AM, Holman AS, Curry WT Jr., Rho MB. Hypertrophic anterior cervical osteophytes causing dysphagia and airway obstruction. Ann Otol Rhinol Laryngol 2009 Oct: 118(10);703-707.

7. Calisaneller T, Ozdemir O, Tosun E, Altinors N. Dysphagia due to diffuse idiopathic skeletal hyperostosis. Acta Neurochir 2005; 147: 1203-1206.

8. Denko CW, Boja B, Moskowitz RW. Growth promoting peptides in osteoarthritis and diffuse idiopathic skeletal hyperostosis - insulin, insulin-like growth factor-l, growth hormone . J Rheumatol 1994; 21(9): 725-730.

9. Miedany YM, Wassif G, Baddini M. Diffuse idiopathic skeletal hyperostosis (DISH): is it of vascular etiology? Clin Exp Rheumatol 2000; 18(2): 193-200.

10. Troyanovich SJ, Buettner M. A structural chiropractic approach to the management of diffuse idiopathic skeletal hyperostosis. J Manipulative Physiol Ther.2003 Mar-Apr; 26(3):202-206.

11. Carlson ML, Archibald DJ, Graner DE, Kasperbauer JL. Surgical management of dysphagia and airway obstruction in patients with prominent ventral cervical osteophytes. Dysphagia. 2011 Mar; 26(1): 34-40. 